\title{
Study of relationship between age and body mass index on knee osteoarthritis in advanced aged females in a divisional city of Bangladesh
}

\author{
Malay K. Roy ${ }^{1 *}$, M. Zakir Hossain ${ }^{1}$, A. H. M. Tanvir Hasan Siddiquee ${ }^{1}$, M. Alauddin', \\ Mohammad K. Islam ${ }^{1}$, A. K. M. Mustafizur Rahman Minto', Tapas K. Sarkar ${ }^{2}$
}

\author{
${ }^{1}$ Department of Ortho-Surgery, Mymensingh Medical College, Mymensingh, Bangladesh \\ ${ }^{2}$ Department of Anaesthesia, Faridpur Medical College (Bangobandhu Sheikh Mujib Medical College), Faridpur, \\ Bangladesh
}

Received: 07 April 2021

Revised: 16 May 2021

Accepted: 17 May 2021

\section{*Correspondence:}

Dr. Malay K. Roy,

E-mail: roymalay25@yahoo.com

Copyright: ( ) the author(s), publisher and licensee Medip Academy. This is an open-access article distributed under the terms of the Creative Commons Attribution Non-Commercial License, which permits unrestricted non-commercial use, distribution, and reproduction in any medium, provided the original work is properly cited.

\begin{abstract}
Background: Knee osteoarthritis is a notable issue in senior citizens and is a burning problem worldwide. There are so many risk factors related to knee osteoarthritis but women's sex, age, and obesity are significant. The aim and objective of this study were to estimate the prevalence of knee osteoarthritis among women in the age group of 46 to 65 years and the effect of age and body mass index (BMI) on knee osteoarthritis.

Methods: Cross-sectional study was conducted at outpatient department (OPD) in Mymensingh Medical College Hospital, a tertiary level hospital, among females of Mymensingh, a divisional city of Bangladesh in the age group of 46 to 65 years. Purposive sampling technique used to select study subjects. A total of 100 females participated in this study in one month (July 2019-August 2019).

Results: 100 participants were enlisted in the study, in the age group of 46 to 55 years 39 (39\%) and 56 to 65 years 61 (61\%). Total $65(65 \%)$ participants were affected with knee osteoarthritis. Among them, 19 (29.2\%) participants were in the age group of 46-55 years and $46(70.8 \%)$ participants were in the age group of 55-65 years, thus in the advanced age group, knee osteoarthritis is remarkably more. Participants affected with knee osteoarthritis with BMI $\geq 25$ were significantly more affected 45 (69.2\%) compared with participants with normal BMI 20 (30.2\%).

Conclusions: Knee osteoarthritis is significantly associated with advanced age and obesity. Advanced age and overweight were strongly associated with osteoarthritis in our population. Therefore, weight reduction and preventive measures can decrease the burden and will help in minimizing morbidity associated with OA.
\end{abstract}

Keywords: Knee osteoarthritis, Females, Age, Obesity, BMI

\section{INTRODUCTION}

Ageing is natural and irreversible process. Due to notable development in medical science life expectancy has increased significantly. Thus increase in life expectancy has brought more morbidity among the senior citizens. Osteoarthritis (OA) is one of the major problems with significant morbidity. It is a chronic degenerative disorder of bone joints characterized by loss of articular cartilage, hypertrophy of bone at the margins and subchondral sclerosis. OA has multi factorial etiologies. Customarily it affects joints of extremities and spine particularly of weight bearing joints. OA of knee is a common cause of pain and disability especially in senior citizens. ${ }^{1}$ Prevalence of the disease is more in women compared to men in advanced life. In Britain, hospital data suggests that 
$1.5 \%$ of people undergo knee surgery (TKA) at some stage in their lives. ${ }^{2}$ In case-control studies have demonstrated a strong relationship between knee OA and obesity. ${ }^{3}$ In Framingham longitudinal study high body mass index (BMI) predicted outcome of the disease in advanced age. ${ }^{4}$ Analysis of women in the same cohort has shown that incidence is downgrade in overweight women who lose weight than in those who do not. ${ }^{5}$ In India prevalence of $\mathrm{OA}$ is around 22 to $39 \% .^{8}$ In Indian population almost $65 \%$ of cases of OA are within the age group of 51-65 years. ${ }^{9}$

The two most important factors for determining the onset of the OA are female sex and age. Study among perimenopausal women prevalence of osteoarthritis was found to be $47.3 \%$ and as age increases prevalence also was increased..$^{10}$ Other causes of knee OA include legal disposition to OA in multiple joints and trauma or surgical intervention to the knee. ${ }^{6}$ As per the report of United Nations about 130 million people by 2050 will have OA worldwide and out of that 40 million will suffer from severe disease. ${ }^{12}$

Study by Fransen et al it was found that prevalence of knee pain or symptomatic knee OA is high among older people in Asian region. ${ }^{13}$ Particularly females in the age group of 45 to 65 years were having complaint of knee pain. Many studies have suggested that gender also a significant factor in osteoarthritis and females are more prone than males and onset of the osteoarthritis earlier than male counterpart. Thus increases the morbidity among females significantly. Gender and age are the major non modifiable risk factors but exercise, diet and trauma are the modifiable risk factors. Symptomatic management is the only option in majority of the cases as there is no definitive treatment. Above data suggest that regulating obesity can reduce risk. Risk is increased many folds when obesity in combination with one or more other risk factors then weight control would be appropriate. Only prevention can reduce the burden of the disease. The objective of the study was to estimate of the prevalence of knee OA among females in age group of 46 to 65 years and to assess the relationship between age and BMI of patient with knee OA.

\section{METHODS}

This cross sectional study was conducted in Mymensingh Medical College Hospital, Mymensingh, Bangladesh. Total 100 female participants were in age group of 46 to 65 years. Purposive sampling technique used to select study subjects. Informed written consent were taken from all study participants. Study duration was one month (July 2019-August 2019). The study method involved was X-ray of knee and measurement of BMI and personal interviews of participants. Inclusion criteria were non traumatic knee pain, age within the range mentioned above and willingness to participation. Exclusion criteria were secondary OA, patients not willing to give consent. Statistical analysis was done with percentages and chi square test. Data were analyzed using statistical package for the social sciences (SPSS) software v.23.0.

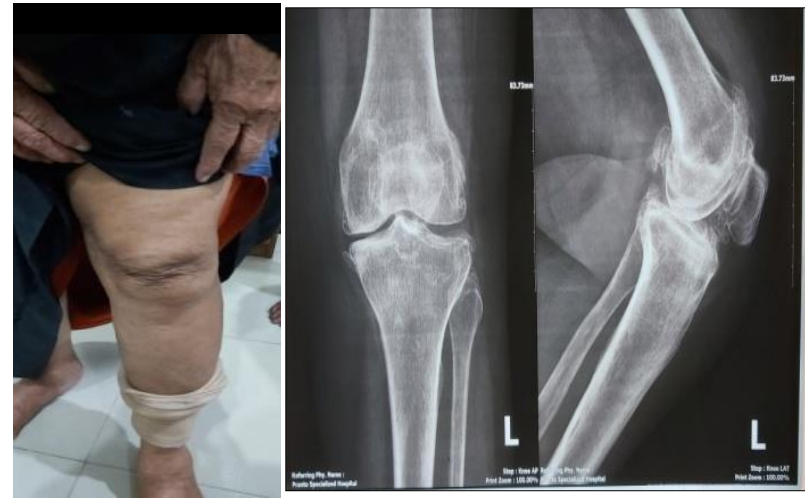

Figure 1. Osteoarthritis of left knee.

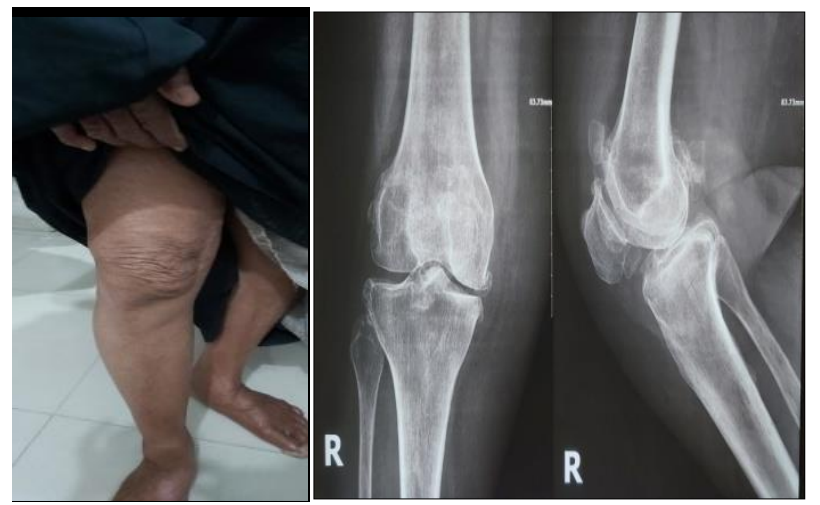

Figure 2: Osteoarthritis of right knee.

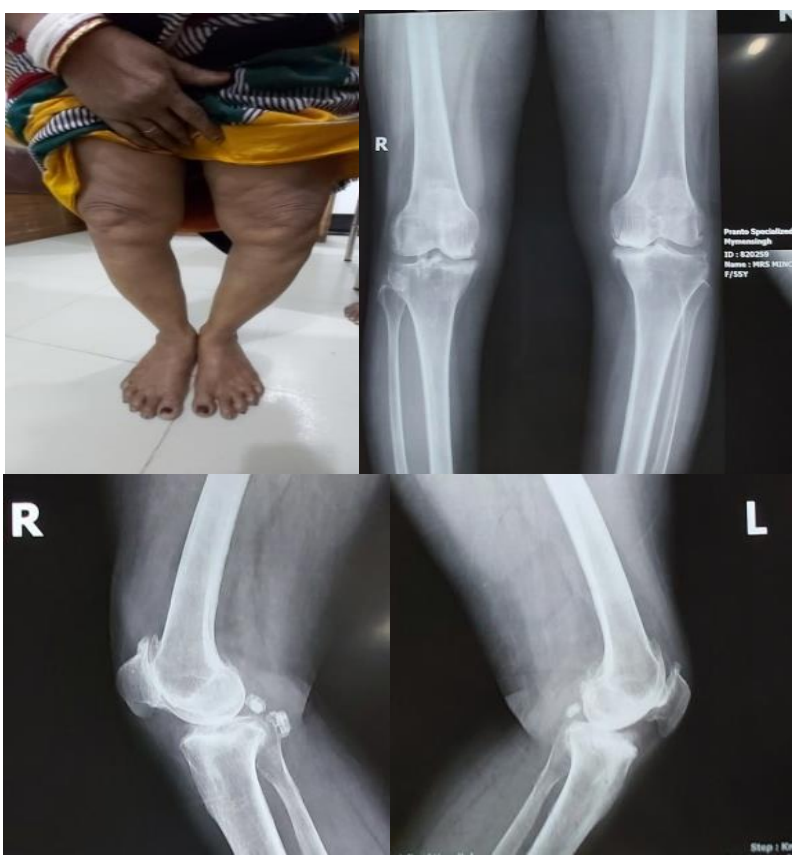

Figure 3: Osteoarthritis of both knees.

\section{RESULTS}

Total 100 participants were enrolled in this study. Mean age of the participants was $56.24 \pm 6.34$. In 100 participants $39(39 \%)$ participants were in age group of 46 to 55 years 
and $61(61 \%)$ were in age group of 56 to 65 years. Total $65(65 \%)$ participants were affected by knee osteoarthritis. Among them $29.2 \%$ were younger age group and $78.2 \%$ were in advanced age. BMI of knee osteoarthritis patients, ranged from $15.4 \%(\leq 18.5), 15.4 \%$ (18.51-24.99) and 69.2 $\%(\geq 25)$ respectively.

Table 1: Demographics characteristics of patients $(\mathbf{n}=100)$.

\begin{tabular}{|ll|}
\hline Demographics characteristics & Mean $\pm \mathrm{SD} / \%$ \\
\hline Age (in years) & $56.24 \pm 6.34$ \\
\hline BMI & $25.41 \pm 5.0$ \\
\hline Age group (in years) & \\
\hline $46-55$ & $39(39)$ \\
\hline $56-65$ & $61(61)$ \\
\hline Osteoarthritis affected & $65(65)$ \\
\hline Not affected & $35(35)$ \\
\hline Osteoarthritis affected $(\mathbf{n = 6 5})$ & \\
\hline $46-55$ & $19(29.2)$ \\
\hline $56-65$ & $46(70.8)$ \\
\hline BMI (n=65) & \\
\hline$\leq 18.50$ & $10(15.4)$ \\
\hline $18.51-24.99$ & $10(15.4)$ \\
\hline$\geq 25$ & $45(69.2)$ \\
\hline
\end{tabular}

Table 2 shows the significant relationship between osteoarthritis patients and age. In advanced age prevalence of knee OA significantly increases i.e. $(70.8 \%$ versus $29.2 \%, \mathrm{p}=0.006)$.

Table 2: Association between knee osteoarthritis patients and age $(n=100)$.

\begin{tabular}{|llll|}
\hline $\begin{array}{l}\text { Age group } \\
\text { (years) }\end{array}$ & $\begin{array}{l}\text { No. } \\
\text { participants } \\
\text { affected }\end{array}$ & $\begin{array}{l}\text { No. } \\
\text { participants } \\
\text { not affected }\end{array}$ & $\begin{array}{l}\text { P } \\
\text { value }\end{array}$ \\
\hline $\mathbf{4 6 - 5 5}$ & $19(29.2)$ & $20(57.1)$ & \multirow{2}{*}{0.006} \\
\hline $56-65$ & $46(70.8)$ & $15(42.9)$ & \\
\hline
\end{tabular}

$\mathrm{P}$ after $\chi^{2}$

Compared to normal weight subjects being overweight increased the risk of OA. Participants with BMI $(\geq 25)$ out of $55,56(81.8 \%)$ participants were affected by knee osteoarthritis which is significantly more $(81.8 \%$ versus $18.2 \% ; \mathrm{p}=0.000$ ) as given in Table 3.

Table 3: Association between knee osteoarthritis patients and BMI $(n=100)$.

\begin{tabular}{|llll|}
\hline BMI & $\begin{array}{l}\text { No. } \\
\text { participants } \\
\text { affected }\end{array}$ & $\begin{array}{l}\text { No. } \\
\text { participants } \\
\text { not affected }\end{array}$ & $\begin{array}{l}\text { P } \\
\text { value }\end{array}$ \\
\cline { 1 - 3 } $\mathbf{\leq 1 8 . 5}$ & $10(41.7)$ & $14(58.3)$ & \\
\cline { 1 - 3 } 0.000 \\
\cline { 1 - 3 } & $10(47.6)$ & $11(52.4)$ & \\
\hline
\end{tabular}

Table 4 shows the relationship between older age and obese with knee OA patients. Knee OA older age patients had significantly higher BMI than normal age patients $(\mathrm{p}=0.012)$.

Table 4: Relationship between BMI and age of the OA patients $(n=65)$.

\begin{tabular}{|lll|}
\hline BMI & Age mean (SD) & P value \\
\hline $\mathbf{1 8 . 5}$ & $54.30 \pm 6.5$ & \\
\cline { 1 - 2 } 0.002 \\
\cline { 1 - 2 } $\mathbf{1 8 . 6 2 4 . 9 9}$ & $55.90 \pm 5.30$ & \\
\hline
\end{tabular}

$\mathrm{P}$ after ANOVA

\section{DISCUSSION}

In present study it was found that females in the age group of 56-65 years of age were having more significant prevalence $46(70.8 \%)$ of knee OA compared to $46-55$ years age group where $19(29.2 \%)$ participants were affected. Out of 65 affected participants $45(69.2 \%)$ were overweight and remaining participants were having normal or BMI within the range of $(\leq 18.5$ to 24.99$)$. Overweight is a major risk factor for knee OA. Compared with the other studies, study conducted by Sharma et al in Chandigarh UT, prevalence was found 56.6\%. In Sharma et al study it was observed that increased BMI was significantly associated with the osteoarthritis. ${ }^{14}$ Other study conducted by Radha et al in Mysore city prevalence among females was found $63.33 \%$ and overweight with obese patients were $37.33 \%$, who were diagnosed with osteoarthritis. ${ }^{15}$ Another study conducted in Maharashtra by Kamble et al, $24.1 \%$ participants in study reported knee osteoarthritis and among them $29 \%$ females were having knee osteoarthritis. ${ }^{16}$ According to Bhandarkar et al study in Mumbai age specific prevalence among females was $63 \% .{ }^{17}$ Other study conducted by Ganvir et al concluded that female sex and age are the risk factors for knee osteoarthritis along with obesity and physically demanding job. ${ }^{18}$

\section{Limitations}

This was a single center study with small sample size. So, the findings might not reflect the scenarios of the whole country.

\section{CONCLUSION}

Due to increase in life expectancy in worldwide osteoarthritis will become one of the commonest diseases of advanced age with large burden on public health services. Over weight and older age were strongly associated with OA in our population. Weight reduction can reduce the disease. Due to absence of definitive treatment and high cost of surgical interventions preventive measures are necessary to reduce the prevalence of disease. Findings of this study will encourage the public health initiatives aimed at reducing 
obesity and identify certain groups thus decrease the future requirements for replacement surgery.

Funding: No funding sources

Conflict of interest: None declared

Ethical approval: The study was approved by the institutional ethics committee

\section{REFERENCES}

1. Cooper C. Epidemiology of Osteoarthritis. In: Klippel JH, Dieppe PA (eds). Rheumatology (2nd edn). Mosby: London. 1998;821-8.

2. Williams M, Frankel S, Nanchahal K, Coast J, Donovan J. Epidemiologically based needs assessment: total knee replacement. Health Care Evaluation Unit, University of Bristol: Bristol. 1992.

3. Spector TD. The fat on the joint: osteoarthritis and obesity. J Rheumatol. 1990;17:283-4.

4. Felson DT, Anderson JJ, Naimark A, Walker AM, Meenan RF. Obesity and knee osteoarthritis. The Framingham Study. Ann Intern Med. 1988;109:1824.

5. Felson DT, Zhang Y, Anthony JM, Naimark A, Anderson JJ. Weight loss reduces the risk for symptomatic knee OA in women: the Framingham Study. Ann Intern Med. 1992;116:535-9.

6. Cooper C, McAlindon T, Snow S, Vines K, Young P, Kirwan J, Dieppe P. Mechanical and constitutional risk factors for symptomatic knee osteoarthritis: differences between medial tibiofemoral and patellofemoral disease. J Rheumatol. 1994;21:307士13

7. Kellgren JH, Lawrence JS. Atlas of Standard Radiographs: The Epidemiology of Chronic Rheumatism. Oxford: Blackwell. 1963.

8. Chopra A, Patil J, Billampelly V, Relwani J, Tandale HS. Prevalence of rheumatic diseases in a rural population in Western India: a WHO-ILAR COPCORD study. J Assoc Physicians India. 2001;49(2):240-6.

9. Bhatia D, Bejarano, T, Novo M. Current Interventions in the Management of Knee Osteoarthritis. J Pharma Bio-allied Sci. 2013;5:30-8.

10. Salve H, Gupta V, Palanivel C, Yadav K, and Singh B. Prevalence of knee osteoarthritis amongst perimenopausal women in an urban resettlement colony in South Delhi. Indian J Public Health. 2010;54:155-7.

11. Kapur P, Sinha B, Pereira BM. Measuring climacteric symptoms and age at natural menopause in an Indian population using the Greene Climacteric Scale. Menopuase. 2009;16(2):378-84.

12. United Nations. World Population 2300. Available at: http://www.un.org/esa/population/publications/ .../World Pop2300final.pdf. Accessed on 10 January 2017.

13. Fransen M, Bridgett L, March Lyn, Hoy D, Penserga E. The epidemiology of osteoarthritis in Asia. Int $\mathbf{J}$ Rheumatic Dis. 2011;14:113-21.

14. Sharma MK, Swami HM, Bhatia V, Verma A, Bhatia SPS, Kaur G. An epidemiological study of correlates of osteo-arthritis in geriatric population of UT Chandigarh. Indian J Comm Med. 2007;1(1):77-8.

15. Radha MS, Gangadhar MR. Prevalence of knee osteoarthritis patients in Mysore city, Karnataka. Int J Recent Sci Res. 2015;6(4):3316-20.

16. Kamble VS, Ghodke YD, Dhumale GB, Avchat SS, Goyal RC. Health status of elderly persons in rural area of India. Indian Medical Gazette. 2012;295299.

17. Bhandarkar P, Patil P, Shekhar C, Kamat N. Prevalence of osteoarthritis knee: four year study based on digital records of comprehensive healthcare setup at Mumbai, India. Int J Comm Med Public Health. 2016;3:1049-53.

18. Ganvir SD, Zambre BR. Prevalence of Identification of Risk Factors for knee osteoarthritis among elderly men and women. Sch J Appl Med Sci. 2013;1(6):700-3.

19. Bost L, Primatesta P, Dong W. Anthropometric measures and children's iron status. In: PrescottClarke P, Primatesta P (eds). Health survey for England' 96. The Stationery Of®ce: London. 1998;282-304.

Cite this article as: Roy MK, Hossain MZ, Siddiquee AHMTH, Alauddin M, Islam MK, Minto AKMMR, et al. Study of relationship between age and body mass index on knee osteoarthritis in advanced aged females in a divisional city of Bangladesh. Int J Res Orthop 2021;7:xxx-Xx. 